\title{
POST CAESAREAN PREGNANCY IN A TERTIARY CARE CENTRE OF TRIBAL AREA OF BASTAR: A SPECIAL CONCERN
}

\author{
Alpana Bansal'1, Indu Sharma², Jyoti Lagoo 3 , Devjanani Raiguru4, Hemant Sharma 5 \\ ${ }^{1}$ Associate Professor, Department of OBG, Late Shree B.R.K.M. Medical College and Associated Maharani Hospital, Jagdalpur, Bastar. \\ ${ }^{2}$ Assistant Professor, Department of OBG, Late Shree B.R.K.M. Medical College and Associated Maharani Hospital, Jagdalpur, Bastar. \\ ${ }_{3}^{3}$ Associate Professor, Department of OBG, Late Shree B.R.K.M. Medical College and Associated Maharani Hospital, Jagdalpur, Bastar. \\ ${ }^{4} J$ unior Resident, Department of OBG, Late Shree B.R.K.M. Medical College and Associated Maharani Hospital, Jagdalpur, Bastar. \\ ${ }_{5}^{5}$ Senior Resident, Department of OBG, Late Shree B.R.K.M. Medical College and Associated Maharani Hospital, Jagdalpur, Bastar.
}

\section{ABSTRACT}

\section{BACKGROUND}

There are different reports available regarding the benefits and risks of Trial of labour after caesarean (TOLAC) in terms of maternal and perinatal outcome.

\section{AIMS}

To study the success rate of VBAC. To analyse the maternal and perinatal outcome in post caesarean pregnancy.

\section{MATERIAL AND METHODS}

This was a prospective study of 1.5 years conducted in the department of Obstetrics and Gynaecology of Late BRKM Medical College and Associated Maharani Hospital, Jagdalpur, Chhattisgarh. We had included all the admitted patients of term pregnancy with one previous CS with informed and written consent. Data were collected and analysed by simple percent and by using SPSS vs. 16 .

\section{RESULT}

Incidence of pregnancy with previous one caesarean at term was $4.5 \%$ and rate of caesarean section was $17 \%$. Incidence of VBAC was only $13.5 \%$ and repeat CS was high as $86.3 \%$. Cases underwent for TOLAC after informed consent were only 62 . Success rate of VBAC was only $45.2 \%$. Outcome of TOLAC was favoured by previous h/o vaginal delivery ( $\mathrm{P}$ value 0.012 ) and average birth weight of the neonates $(\leq 3.0 \mathrm{~kg})$. Most common cause of failure of TOLAC was scar tenderness $(61.8 \%)$; 2 cases $(0.9 \%)$ of rupture uterus was found. Intraoperative incidence of scar dehiscence was 9.2\% (19/206) and 4.8\% (3/62) in the group of trial of labour cases. There was no maternal mortality. Maternal morbidity in the form of puerperal pyrexia, wound infection, need of blood transfusion and hospital stay was more in repeat CS group than VBAC. There were 2 stillbirths in case of VBAC, 4 stillbirths by emergency repeat CS and no stillbirth in elective repeat CS; $66.6 \%$ neonates of severe birth asphyxia were born by emergency CS. Maximum NICU admissions by the neonates of repeat CS. Perinatal mortality rate was $2.9 \%$.

\section{CONCLUSION}

Results of present study shows the relative safety and better maternal and perinatal outcome of TOLAC and VBAC. Even though TOLAC should only be attempted in centres well equipped with comprehensive emergency obstetric care for 24 hours.

\section{KEYWORDS}

Post Caesarean Pregnancy, TOLAC, VBAC, Maternal Outcome, Perinatal Outcome.

HOW TO CITE THIS ARTICLE: Bansal A, Sharma I, Lagoo J, et al. Post caesarean pregnancy in a tertiary care centre of tribal area of Bastar: a special concern. J. Evolution Med. Dent. Sci. 2016;5(61):4295-4300, DOI: 10.14260/jemds/2016/980

\section{INTRODUCTION}

Incidence of primary Caesarean section has increased multifold over the last 20 years. As a result an increasing number of women face the issue of mode of delivery in their subsequent pregnancies.1,2,3 The relative safety of the operative procedure has put a great drain on health care resources, is costly and associated with serious risks to the mother and the baby.

Financial or Other, Competing Interest: None.

Submission 25-06-2016, Peer Review 19-07-2016,

Acceptance 25-07-2016, Published 01-08-2016.

Corresponding Author:

Dr. Indu Sharma,

Assistant Professor,

Department of Obstetrics \& Gynaecology,

Late Shree B.R.K.M. Medical College and

Associated Maharani Hospital,

Jagdalpur, Bastar, Chhattisgarh.

E-mail: georgian.indu@gmail.com

DOI: $10.14260 /$ jemds/2016/980
The rising caesarean section rate has created an expanding high risk obstetric sub-population 'women with scarred uterus.' Cragin's dictum of "once a caesarean always a caesarean" contributed to $30-50 \%$ rise in caesarean rates in the United States till the 1980s.4,5

Ignorance and lack of education, poor understanding of the operation and its subsequent management, both on the part of the patient and her family leads to poor acceptance of both first and repeat caesarean section. Failure to seek antenatal care in subsequent pregnancy, attempts of delivery at home or report late in advanced labour. unskilled vaginal examination by untrained persons and injudicious use of oxytocin leads to high maternal and perinatal morbidity and mortality among women of post-caesarean pregnancy.

However, later because of escalating rates of caesarean section suggestions were made that Vaginal Birth After Caesarean Section (VBAC) might help in reducing rates of caesarean section. There is evidence of safety of trial of labour 
with reduction in iatrogenic prematurity and maternal morbidity and mortality. In an appropriate clinical setting and properly selected group of women, VBAC is safe and effective. ${ }^{6}$

The dictum "once a caesarean always a caesarean" no longer holds true. The dictum now is "once a caesarean section, always an institutional delivery in a well-equipped hospital." Both attempting vaginal birth and opting for an elective repeat caesarean section are associated with different risks of mother and new-born; and deciding a delivery plan involves a difficulty weighing of those cases. ${ }^{7}$

Present study was undertaken with the aim to decide appropriate mode of delivery and to conduct the proper management of patients with previous one caesarean as well as to analyse the maternal and perinatal outcome. We also analysed the factors affecting success of trial of labour.

\section{MATERIAL AND METHODS}

The present study was a prospective observational study, undertaken in the Department of Obstetrics and Gynaecology of Government Medical College and Associated Maharani Hospital, Jagdalpur, Chhattisgarh, between 01.07.2012 to 31.01.2014 over 206 cases of previous one caesarean section.

\section{Inclusion Criteria}

1. Pregnant women at term gestation with $\mathrm{H} / \mathrm{O}$ previous one L.S.C.S. not in labour or in labour with cephalic presentation and singleton pregnancy.

2. Previous L.S.C.S done without any intra-op complications like scar dehiscence or rupture or classical caesarean to ensure scar integrity.

\section{Exclusion Criteria}

1. Pregnancies with H/O 2 or more L.S.C.S, myomectomy scar or hysterotomy scar.

2. Twin pregnancy or multiple pregnancy and malpresentation.

3. Any medical or obstetrical complications.

\section{METHODOLOGY}

Data were recorded by taking detail history and thorough clinical examination. Scar tenderness was elicited at the time of admission. Women with a prior $\mathrm{H} / \mathrm{O}$ one uncomplicated LSCS in an otherwise uncomplicated pregnancy at term with no contraindications to vaginal birth were given the option of a planned VBAC. Before an attempted vaginal delivery, patients were informed about the risks, benefits, potential complications and alternatives to a Trial of Labour After Caesarean (TOLAC). Induction was done by IV oxytocin method only in 6 cases, rest others are allowed to go for spontaneous vaginal delivery with careful intrapartum monitoring. Six-hour rule was observed in active labour wherein TOLAC was terminated after 6 hours of active labour, if vaginal delivery was not imminent. The outcome of delivery, success of TOLAC and outcome of VBAC were recorded. Postpartum complications like $\mathrm{PPH}$, blood transfusion, ruptured uterus, scar dehiscence, puerperal pyrexia, hysterectomy, etc. were noted. Intra-op findings during repeat caesarean in terms of difficulties in opening of abdomen due to adhesions and condition of the uterine scar were noted. Perinatal outcome were recorded in terms of live birth, stillbirth, IUD, APGAR score at $1 \mathrm{~min}$ and 5 mins., fetal weight,
NICU admission, condition at discharge and perinatal mortality.

Women who presented with $\mathrm{H} / \mathrm{O}$ recurrent indication like CPD with no living issue, IUGR and severe oligohydramnios, with foetal distress and non-reassuring FHS and not willing for TOLAC were taken up for repeat L.S.C.S. Women presenting in labour room with signs of impending rupture or scar dehiscence and unsuccessful TOLAC were immediately taken up for emergency L.S.C.S.

\section{Statistical Analysis}

Statistical analysis was performed using SPSS vs. 16. Chi square test of proportion and 2 proportion 'Z' test was applied to see the difference in proportions of parameters.

\section{RESULTS}

In our institute during study period of 1.5 years, total deliveries were 4852. The incidence of pregnancy with previous one caesarean admitted in the department at term for their delivery was $4.5 \%$ (218/4852) and rate of caesarean delivery was $17 \%(824 / 4852)$ [Table 1].

Most of the cases with previous one caesarean were less than 30 years ( $50.5 \%$ cases were $23-27$ years). Their mean age was 26.44 years (SD 3.67) [Table 2].

Among 206 cases of pregnancy with previous one scar only, $13.5 \%$ were delivered by vaginal route (VBAC) whether unassisted (20) or assisted (8) by forceps (1) or vacuum (7) and $86.3 \%$ were delivered by caesarean section whether emergency (60.1\%) or elective (26.2\%) [Table 3].

Only 62 cases were given trial of labour. The success rate of TOLAC was only $45.2 \%$ (28/62) [Table 4]. Success rate of TOLAC (VBAC) was significantly associated with $\mathrm{h} / \mathrm{o}$ previous vaginal delivery ( $\mathrm{p}$ value 0.012 ) as data is showing that among 28 cases of VBAC, $64.2 \%$ cases $(18 / 28)$ have h/o successful previous vaginal delivery, while only $35.7 \%$ cases of VBAC have no h/o any previous vaginal delivery [Table 5]; $89.2 \%$ neonates $(25 / 28)$ born by VBAC were $\leq 3 \mathrm{~kg}$ and only 1 neonate had birth weight $\geq 3.5 \mathrm{~kg}$. On the other hand, most of the neonates born by caesarean had birth weight of $2.6-3.5 \mathrm{~kg}$ (66.5\% by elective repeat CS and $61.2 \%$ by emergency repeat CS) and 5 neonates had birth weight $>3.5 \mathrm{~kg}$ [Table 6].

Most common cause of failure of TOLAC was scar tenderness $(61.8 \%)$ followed by non-progress of labour (26.5\%) and fetal distress (11.7\%) [Table 7].

Out of 178 cases those had undergone repeat CS, we observed Cephalopelvic Disproportion (CPD) as the most common (48.1\%) indication of elective repeat CS and Premature Rupture of Membrane (PROM) along with impending rupture of scar as the common indications $(31.1 \%$, $18.8 \%$ ) of emergency repeat CS, whereas scar tenderness (61.7\%) and non-progress of labour (26.4\%) was found as common indications for emergency repeat CS in failed TOLAC [Table 8].

Among the $47 / 178$ cases of repeat CS, we encountered difficulties in $12.3 \%$ cases in the form of adhesions between anterior abdominal wall and uterus and in $14 \%$ cases, adhesion between omentum, peritoneum and bladder [Table 9]. In $29.4 \%$ cases of failed TOLAC there was thinned out uterine scar, while in only $7.6 \%$ cases of direct repeat CS the uterine scar was thinned out ( $p$ value 0.0004 ). Incidence of scar dehiscence was 9.2\% [Table 10]. 
On analysis of maternal morbidities, we found $90.9 \%$ (10/11) women of repeat CS developed puerperal pyrexia, in comparison to only $9 \%(1 / 11)$ cases of VBAC ( $p$ value $<0.001)$. In the same way, all the cases (100\%) of wound infection were of repeat CS (5/5) and 40\% cases of VBAC had postpartum haemorrhage vs. $60 \%$ cases of repeat CS ( $p$ value 0.27 ). Significantly, higher number of cases ( $p$ value $<0.001$ ) delivered by repeat CS (80.3\%) required blood transfusion than delivered by VBAC (19.6\%). In our study, hysterectomy was not done even for a single case and there was no maternal mortality. Duration of hospital stay was definitely more ( $>3$ days) among the patients of repeat CS [Table 11].

In our study, there were 6 stillbirths and 200 live births; 2 stillbirths were in rupture uterus, 2 stillbirths in obstructed labour (delivered by emergency LSCS) and 2 stillbirths in case of VBAC due to sever fetal distress (Meconium stained liquor). These 2 patients of VBAC with stillbirth reached to our labour room at full dilatation with severe fetal bradycardia after handling at home and one delivered by forceps and another delivered by vacuum; $66.6 \%$ stillbirths were of emergency caesarean and only 33.3\% stillbirths were of VBAC [Table 12]. Only 3 neonates had severe birth asphyxia (66.6\% neonates were born by emergency CS and only $33.3 \%$ by VBAC which is highly significant, $p$ value $<0.001$ ). None of the neonates delivered by elective CS had severe birth asphyxia [Table 13a]. In 43 NICU admissions $72 \%$ were born by emergency CS, $18.6 \%$ by elective repeat CS and only $9.3 \%$ neonates by VBAC [Table 13b].

\begin{tabular}{|c|c|c|}
\hline No. of deliveries & 4852 & \\
\hline Cases with previous one scar & 218 & $4.5 \%$ \\
\hline No. of Caesarean Section & 824 & $17 \%$ \\
\hline Table 1 \\
\hline
\end{tabular}

\begin{tabular}{|c|c|c|c|}
\hline Sl. No. & Age (Years) & N=206 & \% \\
\hline 1. & $18-22$ & 31 & 15 \\
\hline 2. & $23-27$ & 104 & 50.5 \\
\hline 3. & $28-32$ & 59 & 28.6 \\
\hline 4. & $33-37$ & 10 & 4.9 \\
\hline 5. & $38-42$ & 2 & 1.0 \\
\hline & Mean Age & 26.44 & \\
\hline & SD & 3.67 & \\
\hline \multicolumn{3}{|c|}{ Table 2: Clinical Profile } \\
\hline 1. & Booked/Unbooked & $\mathrm{N}=206$ & $\%$ \\
\hline 2. & Unbooked & 37.9 \\
\hline
\end{tabular}

\begin{tabular}{|c|c|c|c|}
\hline & Mode of Delivery & $\mathbf{N = 2 0 6}$ & $\mathbf{\%}$ \\
\hline 1. & VBAC & 28 & 13.5 \\
\hline & Unassisted & 20 & \\
\hline & Vacuum & 7 & \\
\hline & Forceps & 1 & \\
\hline 2. & Emergency LSCS & 124 & 60.1 \\
\hline 3. & Elective LSCS & 54 & 26.2 \\
\hline \multicolumn{3}{|c|}{ Table 3: Mode of Delivery in Present Pregnancy } \\
\hline
\end{tabular}

\begin{tabular}{|c|c|c|c|}
\hline Sl. No. & Outcome of TOLAC & Cases (n=62) & \% \\
\hline 1. & Successful & 28 & 45.2 \\
\hline 2. & Failed & 34 & 54.8 \\
\hline \multicolumn{3}{|c|}{ Table 4: Outcome of TOLAC } \\
\hline
\end{tabular}

\begin{tabular}{|c|c|c|c|}
\hline Sl. No. & Cause & Cases (n=34) & $\mathbf{\%}$ \\
\hline 1. & Scar Tenderness & 21 & 61.8 \\
\hline 2. & NPOL $^{*}$ & 9 & 26.5 \\
\hline 3. & Foetal Distress & 4 & 11.7 \\
\hline \multicolumn{3}{|c|}{ Table 5: Causes of Failed TOLAC } \\
\hline
\end{tabular}

*NPOL non-progress of labour

\begin{tabular}{|c|c|c|c|c|c|c|}
\hline \multirow{2}{*}{$\begin{array}{c}\text { Sl. } \\
\text { No. }\end{array}$} & $\begin{array}{c}\text { Previous } \\
\text { Vaginal } \\
\text { Delivery }\end{array}$ & \multicolumn{2}{|c|}{ VBAC } & \multicolumn{2}{|c|}{$\begin{array}{c}\text { Failed } \\
\text { TOLAC }\end{array}$} & \multirow{2}{*}{$\begin{array}{c}\text { P } \\
\text { value }\end{array}$} \\
\cline { 3 - 6 } & N=28 & \% & N=34 & \% & \\
\hline 1. & h/o & 18 & 64.2 & 11 & 32.3 & 0.012 \\
\hline 2. & No h/o & 10 & 35.7 & 23 & 67.6 & $*$ \\
\hline \multicolumn{6}{|c|}{$\begin{array}{r}\text { Table 6: Outcome of TOLAC in Relation } \\
\text { to Previous Vaginal Delivery }\end{array}$} \\
\hline
\end{tabular}

Chi square test ${ }^{*} \mathrm{p}<0.05$ significant difference.

\begin{tabular}{|c|c|c|c|c|c|c|}
\hline \multirow{2}{*}{$\begin{array}{c}\text { Birth } \\
\text { Weight }\end{array}$} & \multicolumn{2}{|c|}{ VBAC } & \multicolumn{2}{c|}{$\begin{array}{c}\text { Elective } \\
\text { Repeat CS }\end{array}$} & \multicolumn{2}{c|}{$\begin{array}{c}\text { Emergency } \\
\text { Repeat CS }\end{array}$} \\
\cline { 2 - 7 } & $\mathbf{N = 2 8}$ & $\mathbf{\%}$ & $\mathbf{N = 5 4}$ & $\mathbf{\%}$ & $\mathbf{N = 1 2 4}$ & \% \\
\hline$<2.5 \mathrm{~kg}$ & 11 & 39.2 & 13 & 24.0 & 48 & 38.7 \\
\hline $2.6-3.0 \mathrm{~kg}$ & 14 & 50.0 & 21 & 38.8 & 57 & 45.9 \\
\hline $3.1-3.5 \mathrm{~kg}$ & 2 & 7.1 & 15 & 27.7 & 19 & 15.3 \\
\hline$>3.5 \mathrm{~kg}$ & 1 & 3.5 & 5 & 9.2 & 0 & 0 \\
\hline
\end{tabular}

Table 7: Birth Weight as per Mode of Delivery

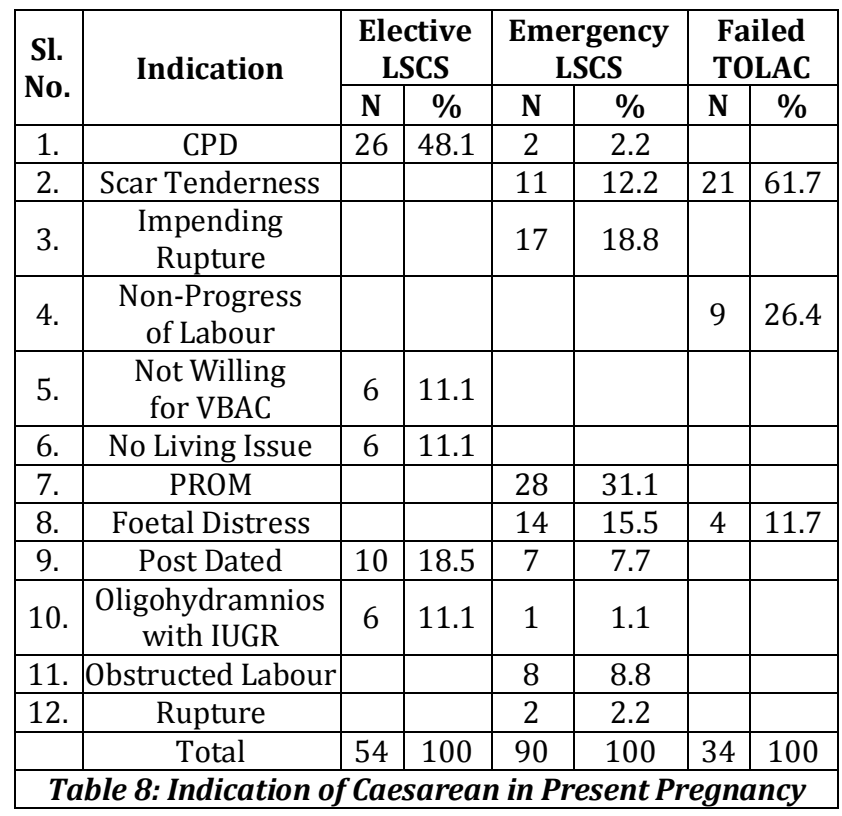

\begin{tabular}{|c|c|c|c|}
\hline Sl. No. & Difficulties & $\mathbf{N = 1 7 8}$ & $\%$ \\
\hline 1. & $\begin{array}{c}\text { Adhesion between Anterior } \\
\text { Abdominal Wall and Uterus }\end{array}$ & 22 & 12.3 \\
\hline 2. & $\begin{array}{c}\text { Adhesion between Omentum, } \\
\text { Peritoneum and Bladder }\end{array}$ & 25 & 14.0 \\
\hline \multicolumn{3}{|c|}{ Table 9: Difficulties Encountered during Repeat CS } \\
\hline
\end{tabular}

\begin{tabular}{|c|c|c|c|c|c|c|}
\hline \multirow{2}{*}{$\begin{array}{c}\text { Sl. } \\
\text { No. }\end{array}$} & \multirow{2}{*}{$\begin{array}{c}\text { of Scar } \\
\text { of Scan }\end{array}$} & \multicolumn{2}{|c|}{ No TOLAC } & \multicolumn{2}{c|}{$\begin{array}{c}\text { Failed } \\
\text { TOLAC }\end{array}$} & \multirow{2}{*}{ P value } \\
\cline { 3 - 7 } & $\mathbf{N = 1 4 4}$ & $\mathbf{\%}$ & $\mathbf{N}=\mathbf{3 4}$ & $\mathbf{\%}$ & \\
\hline 1. & Thinned Out Scar & 11 & 7.6 & 10 & 29.4 & $0.0004^{*}$ \\
\hline 2. & Scar Dehiscence & 16 & 11.1 & 3 & 8.8 & 0.69 \\
\hline 3. & Ruptured Uterus & 2 & 1.38 & 0 & 0 & 0.49 \\
\hline \multicolumn{7}{|c|}{ Table 10: Condition of Uterine Scar during Repeat CS } \\
\hline
\end{tabular}

2 proportion ' $\mathrm{z}$ ' test, $\quad{ }^{*} \mathrm{p}<0.001$ highly significant 


\begin{tabular}{|c|c|c|c|c|c|c|c|}
\hline \multirow{2}{*}{$\begin{array}{l}\text { Sl. } \\
\text { No. }\end{array}$} & \multirow{2}{*}{\begin{tabular}{|c|} 
Maternal \\
Morbidities
\end{tabular}} & \multirow{2}{*}{$\mathbf{N}$} & \multicolumn{2}{|c|}{ VBAC } & \multicolumn{2}{|c|}{ Repeat CS } & \multirow{2}{*}{$P$ value } \\
\hline & & & \begin{tabular}{|l|} 
Cases \\
\end{tabular} & $\%$ & Cases & $\%$ & \\
\hline 1. & $\begin{array}{l}\text { Puerperal } \\
\text { Pyrexia }\end{array}$ & 11 & 1 & 9.0 & 10 & 90.9 & $<0.001^{* *}$ \\
\hline 2. & $\begin{array}{l}\text { Wound } \\
\text { Infection }\end{array}$ & 5 & 0 & 0 & 5 & 100 & $<0.001^{* *}$ \\
\hline 3. & $\begin{array}{l}\text { Adherent } \\
\text { Placenta }\end{array}$ & 2 & 1 & 50 & 1 & 50 & 1 \\
\hline 4. & $\mathrm{PPH}$ & 15 & 6 & 40 & 9 & 60 & 0.27 \\
\hline 5. & $\begin{array}{l}\text { Need of Blood } \\
\text { Transfusion }\end{array}$ & 51 & 10 & 19.6 & 41 & 80.3 & $<0.001^{* *}$ \\
\hline 6. & Hysterectomy & 0 & 0 & 0 & 0 & 0 & --- \\
\hline 7. & $\begin{array}{c}\text { Duration of } \\
\text { Hospital Stay }\end{array}$ & & & & & & \multirow{4}{*}{$<0.001^{* *}$} \\
\hline & Upto 3 Days & 22 & 22 & 100 & 0 & 0 & \\
\hline & 4-8 Days & 176 & 6 & 3.4 & 170 & 96.5 & \\
\hline & $>8$ Days & 8 & 0 & 0 & 8 & 100 & \\
\hline
\end{tabular}

2 proportion ' $\mathrm{z}$ ' test ${ }^{* *} \mathrm{p}<0.001$ highly significant

\begin{tabular}{|c|c|c|c|c|}
\hline \multirow{2}{*}{ Mode of Delivery } & \multicolumn{2}{|c|}{ Live Birth } & \multicolumn{2}{c|}{ Still Birth } \\
\cline { 2 - 5 } & $\mathbf{N}=\mathbf{2 0 0}$ & $\mathbf{9}$ & $\mathbf{N = 6}$ & $\mathbf{\%}$ \\
\hline VBAC & 26 & 13 & 2 & 33.3 \\
\hline Elective Repeat CS & 54 & 27 & 0 & 0 \\
\hline Emergency Repeat CS & 120 & 60 & 4 & 66.6 \\
\hline
\end{tabular}

Table 12: Neonatal Outcome as per Mode of Delivery

\begin{tabular}{|c|c|c|c|c|c|c|}
\hline \multirow{3}{*}{$\begin{array}{c}\text { Mode of } \\
\text { Delivery }\end{array}$} & $\begin{array}{c}\text { Normal } \\
\mathbf{( 7 - 1 0 )}\end{array}$ & $\begin{array}{c}\text { Intermediate (4- } \\
\mathbf{6})\end{array}$ & $\begin{array}{c}\text { Severe } \\
\text { (<4) }\end{array}$ \\
\cline { 2 - 7 } & $\mathbf{N = 1 6 5}$ & $\mathbf{\%}$ & $\mathbf{N = 3 2}$ & $\mathbf{\%}$ & $\mathbf{N}=\mathbf{3}$ & $\mathbf{\%}$ \\
\hline VBAC & 23 & 13.9 & 2 & 6.2 & 1 & 33.3 \\
\hline $\begin{array}{c}\text { Elective Repeat } \\
\text { CS }\end{array}$ & 51 & 30.9 & 3 & 9.3 & 0 & 0 \\
\hline $\begin{array}{c}\text { Emergency } \\
\text { Repeat CS }\end{array}$ & 91 & 55.1 & 27 & 84.3 & 2 & 66.6 \\
\hline \multicolumn{7}{|c|}{ Table 13(a): Analysis of Perinatal Outcome } \\
as per Mode of Delivery \\
\hline
\end{tabular}

\begin{tabular}{|c|c|c|c|}
\hline \multirow{2}{*}{$\begin{array}{c}\text { Sl. } \\
\text { No. }\end{array}$} & \multirow{2}{*}{ Mode of Delivery } & \multicolumn{2}{|c|}{ NICU Admission } \\
\hline & & $\mathrm{N}=43$ & $\%$ \\
\hline 1 & Elective Repeat CS & 8 & 18.6 \\
\hline 2 & Emergency Repeat CS & 31 & 72.0 \\
\hline 3 & VBAC & 4 & 9.3 \\
\hline \multicolumn{4}{|c|}{$\begin{array}{c}\text { Table 13(b): Analysis of Perinatal Outcome } \\
\text { as per Mode of Delivery }\end{array}$} \\
\hline
\end{tabular}

\section{DISCUSSION}

In today's situation when the access to obstetric care is growing day by day, there has been a concern with the rising caesarean rates over the world.(8) The introduction of LSCS gave a good and strong scar to the uterus to hold and safely deliver a subsequent pregnancy. It is now safe to say that "Once a caesarean section always a hospital delivery."(9) New evidence is emerging to indicate that VBAC may not be as safe as originally thought. $(10,11)$ But reports are conflicting and these factors along with medicolegal concerns have led to a decline in clinicians offering and women accepting trial for VBAC in various parts of the world. $(5,12)$
Out of 4852 patients who delivered in our hospital during the study period, the incidence of pregnancy with previous one caesarean at term was $4.5 \%$. This incidence is comparable to study of Gonen and Colleagues (5.8\%) and study of Gupta P et al $(3.33 \%) .(13,14)$ Our incidence though is lower than the study of Landon et al $(12.16 \%)$ and other Indian studies. $(10,15,16,17,18)$

Incidence rate of caesarean section in our hospital was $17 \%$. WHO has recommended an optimal caesarean rate of 10 $15 \%$.(19) Most of the patients were <28 years (65.5\%) with mean age of 26.44 years (SD 3.67) similar to other Indian studies indicates childhood marriage and early conception.(14,16,20,21)

In our study out of 206 study cases, rate of repeat CS was $86.3 \%$ (Elective repeat CS $26.2 \%$ and emergency repeat CS $60.1 \%$ ). Only $13.5 \%$ cases were delivered vaginally, which is comparable with the study of Najma KP et al (11.87\%).(20) Landon et al and Sharma A et al reported the incidence of VBAC $28.57 \%$ and $27.45 \%$ respectively.(10,15) Gonen and Colleagues and Dr. S. Manikya Rao had reported the incidence of VBAC as $51.22 \%$ and $48 \%$ respectively in their study. ${ }^{(13,22)}$ Out of 206 patients, only 62 patients were given a trial of VBAC and success rate was $45.2 \%(28 / 62)$, which is similar to the study of Anagha A Jinturkar et al (46.7\%).(17) Landon et al and Gonen and Colleagues reported a success rate of $73.41 \%$ and $79.66 \%$ respectively.(10,13) Other studies also showed higher rates of successful VBAC.(14,16,18,20,22-25) The probable reason for this low success rate of VBAC were that most of the cases presented in the labour room in advanced labour and were taken up for emergency repeat L.S.C.S for various indications like impending rupture, fetal distress, etc. along with nonavailability of notes of previous LSCS as $37.9 \%$ cases were unbooked. Most of the cases were referred from remote tribal area, they have already undergone for trial of labour either at home or some primary referral centre. We did not allow them further trial and decision was taken for early caesarean. Similar to the study of Mugdha L Jungari et al (43.75\%) and Singh AK et al, most common cause of failure of TOLAC was scar tenderness seen in 21 cases $(61.8 \%)$ because of late presentation to our labour room and short inter-pregnancy interval.(21,26) Similar to other studies, success rate of TOLAC was improved by the history of previous vaginal delivery (VBAC rate was $64.2 \%$ vs $35.7 \%$ in the group of cases with $\mathrm{h} / \mathrm{o}$ previous vaginal delivery vs no $h / o$ previous vaginal delivery), $\mathrm{p}$ value $0.012 .(14,17,18,20-24)$. Another factor affecting success rate of VBAC was birth weight of baby. Birth weight of $\leq 3.0 \mathrm{~kg}$ had successful vaginal delivery similar to the study of Wanyonyi and Karuga.(27) Mugdha L Jungari et al(21) and Balachandran L et al.(24)

$26.2 \%$ cases were taken up for elective repeat LSCS with the most common indication of CPD (48.1\%) followed by postdated $(18.5 \%) ; 11.1 \%$ cases were not willing for trial of labour and VBAC with the fear of risk of rupture of uterus; $43.6 \%$ $(90 / 206)$ cases were directly taken up for emergency repeat CS. PROM was the most common indication (31.1\%) followed by impending rupture (18.8\%), foetal distress $(15.5 \%)$ and scar tenderness $(12.2 \%) ; 8$ cases $(8.8 \%)$ were taken up for obstructed labour and 2 cases were of previous scar with ruptured uterus. Being a tribal area, delay in reaching the tertiary care centre on time and trial at home or some peripheral centre leads to high rate of emergency repeat CS.

The main difficulties encountered in the present study while doing a repeat CS were difficulty in opening of abdomen 
due to dense adhesions in $12.3 \%$ of the cases and adhesions between omentum, peritoneum and bladder in $14.0 \%$, while Najma et al found difficulty in opening the abdomen due to dense adhesion in $43 \%$ cases and in $38 \%$ cases adhesion between omentum, peritoneum and bladder.(20) Dr. S Manikya Rao et al and Anagha A Jinturkar et al had found adhesion in opening the abdomen as well as adhesion between omentum, peritoneum and bladder during repeat CS similar to our study.(17,22) Incidence of scar dehiscence was 9.2\% (19/206) and ruptured uterus was $0.9 \%(2 / 206)$ similar to the study of Suman Poddar.(16) which is much higher than other studies.(17,20,22,23,28)

There were 2 cases of ruptured uterus, which are presented as rupture on admission, but no rupture was found among TOLAC group. We had seen higher number of cases with thinned out scar (29.4\%) in failed TOLAC cases than among the cases directly taken up for CS (7.6\%), which is statistically significant ( $p$ value 0.0004 ) similar to other studies.(14,23)

On analysing maternal morbidities, we observed statistically significant morbidities ( $p$ value $<0.001$ ) in the form of puerperal pyrexia ( $90.9 \%$ vs. $9.0 \%$ ), wound infection ( $100 \%$ vs. $0 \%$ ), need of blood transfusion ( $80.3 \%$ vs. $19.6 \%$ ) and hospital stay among repeat CS group than cases undergoing VBAC. There was no maternal mortality. In the study of Pratiksha Gupta et al(14) morbidities were more in emergency CS following TOLAC. Conversely, Landon et al(10) observed the risks of transfusion and infections were significantly greater for women attempting TOLAC. Bhat BPR et al(18) observed increased need of blood transfusion in caesarean cases (3.7\%) than VBAC cases (2.7\%). Goel SS et al also reported significantly more maternal complications in the form of PPH and need of blood transfusion in cases undergoing repeat CS whether emergency or elective than delivered vaginally.(23) It has generally been accepted that vaginal delivery is associated with lower rates of maternal morbidities and mortalities than repeat CS. Our results are comparable to Najma K P et al, Nigam A et al, Mercer et al and the other an earlier meta-analysis.(20,28-30)

The perinatal outcome of our study shows higher morbidity as well as mortality along with NICU admissions are found among the neonates born by emergency CS than VBAC and elective repeat CS. Our results are comparable with other studies also.(18,23) The study of Sharma A et al(15), Suman Poddar(16), Anagha A Jinturkar et al(17), Dr. Najma K P et al(20), Dr. S Manikya Rao et al(22) and Nigam A et al(28) are suggesting comparatively better perinatal outcome of VBAC than repeat CS.

Current recommendations of the RCOG and ACOG include offering the option of a planned VBAC to women with a prior history of one uncomplicated LSCS in an otherwise uncomplicated pregnancy at term with no contraindication to vaginal birth.(31,32) Stress must be laid on proper antenatal counseling regarding the benefits and risks associated with a planned VBAC. A final decision for mode of birth must be agreed upon before the expected date of delivery (Ideally at 36 weeks of gestation). VBAC should always be attempted in institutions well equipped to respond to emergencies with an OT facility and adequate trained personnel to provide emergency care.

\section{CONCLUSION}

In our study, vaginal deliveries have a much safer outcome than repeat CS with decreased maternal morbidity and perinatal morbidity and mortality. In order to decrease the rising rate of caesarean section, it is essential to counsel the women with $\mathrm{h} / \mathrm{o}$ prior LSCS during antenatal period regarding benefits and risks of the VBAC, enabling them to make an informed choice and opt for TOLAC. However, TOLAC should only be attempted in centre well equipped with comprehensive emergency obstetric care and with facilities for emergency 24-hour caesarean section. Result of our study emphasizes the need of education and awareness, improvement in health resources and transport facilities from remote tribal areas as well as frequent antenatal visits.

\section{ACKNOWLEDGEMENTS}

I would like to thank the faculty and staff of my Department and Maharani Hospital, specially my HOD Dr. Prabha Chauhan, for their substantial contributions. I would also like to thank all the study participants.

\section{REFERENCES}

1. Curtin SC. Rates of caesarean birth and VBAC, 1991-95. Monthly vital Statistics report. Hyattsville (MD): National center for Health statistics, 1997;45(11)Suppl 3:1-12.

2. Rates of caesarean delivery-United States, 1991-MMWR Morb Mortal Wkly Rep 1993;42:285-9.

3. Stafford RS. Alternative strategies for controlling rising caesarean section rates. JAMA 1990;263(5):683-7.

4. Cragin EB. Conservatism in obstetrics. NY Med J 1916;104:1-3.

5. Menacker F, Curtin SC. Trends in caesarean birth and vaginal birth after previous caesarean 1991-99. Natl Vital Stat Rep 2001;49(13):1-16.

6. Mukherjee SN. Rising caesarean section rate. J Obstet Gynaecol India 2006;56(4):298-300.

7. Cunningham FG, Bangdiwala SI, Brown SS, et al. NIH consensus development conference statement on vaginal birth after cesarean: new insights. Obstet Gynecol 2010;115:1279-95.

8. Choudhary CR. Caesarean births: the Indian scenario. Population Association of America 2008:1-18.

9. Dodd J, Crowther CA. VBAC: a survey of practice in Australia and New Zealand. Aust NZ J Obstet Gynecol 2010;116:450-63.

10. Landon MB, Hauth JC, Lenovo KJ, et al. Maternal and perinatal outcomes associated with a trial of labour after prior caesarean delivery. N Engl J Med 2004;351(25):2581-9.

11. Smith JC, Pell JP, Cameron AD, et al. Risk of perinatal death associated with labour after previous caesarean delivery in uncomplicated term pregnancies. JAMA 2002;287(20):2684-90.

12. Yeh J, Wactawski-Wende J, Shelton JA, et al. Temporal trends in the rates of trial of labour in low risk pregnancies and their impact on the rates and success of vaginal birth after caesarean delivery. Am J Obstet Gynecol 2006;194(1):144.

13. Gonen R, Nisenblat V, Barak S, et al. Results of a welldefined protocol for a trial of labour after prior caesarean section. Obstet Gynecol 2006;107(2 Pt 1):240-5. 
14. Gupta P, Jahan I, Jograjiya GR. Is vaginal delivery safe after previous lower segment caesarean section in developing country? Niger Med J 2014;55(3):260-5.

15. Sharma A, Sharma U, Chaudhary P, et al. Maternal and neonatal outcome in patients with history of previous one caesarean section. Indian Medical Gazette 2012:169-73.

16. Poddar S. A study of the outcome of subsequent pregnancy following previous caesarean section. Journal of Evolution of Medical and Dental Sciences 2014;3(6):1466-73.

17. Jinturkar AA, Dongaonkar D. Study of obstetric and fetal outcome of post caesarean section pregnancy at tertiary care centre. International Journal of Recent Trends in Science And Technology 2014;10(3):530-7.

18. Bhat BPR, Savant R, Kamnath A. Outcome of a post caesarean pregnancy in a tertiary centre of a developing country. Journal of Clinical and Diagnostic Research 2010;3:2005-9.

19. World Health Organization. Appropriate technology for birth. Lancet 1985;2(8452):436-7.

20. Najma KP, Rao SB. Pregnancy outcome in women with previous one caesarean section. IJSR-International Journal of Scientific Research 2015;4(1):375-7.

21. Jungari ML, Daver RG, Palv T. Factors predicting success of trial of labour among women with previous one caesarean delivery in a developing country. IJIMS 2014;1(8):144-8.

22. Rao SM, Sravanthi S, Sandhya B. Maternal and fetal outcome following trial of labour after previous caesarean section (TOLAC). IOSR Journal of Dental and Medical Sciences (IOSR-JDMS) 2016;15(1):71-8.

23. Goel SS, Tiwari M, Hariharan $C$, et al. Outcome of post caesarean pregnancy and comparison of maternal and foetal outcome following vaginal birth versus repeat caesarean section in a rural hospital. Int J Reprod Contracept Obstet Gynaecol 2013;2(1):16-22.
24. Balachandran L, Vaswani PR, Mogotlane R. Pregnancy outcome in women with previous one caesarean section. Journal of Clinical and Diagnostic Research 2014;8(2):99102.

25. Bangal VB, Giri PA, Shinde KK, et al. Vaginal birth after caesarean section. N Am J Med Sci 2013;5(2):140-4.

26. Singh AK, Goswami D, Dixit RR, et al. Study of frequency and indications of caesarean section in a tertiary care hospital of Garhwal-Uttarakhand, India. Journal of Research in Medical Education and Ethics 2011;1(2):1224.

27. Wanyonyi SZ, Karuga RN. The utility of clinical care pathways in determining perinatal outcomes for women with one previous caesarean section; a retrospective service evaluation. BMC Pregnancy and Childbirth 2010;10:62.

28. Nigam A, Anand R, Jain N. Study of obstetric and fetal outcome of post-caesarean pregnancy. International Journal of Reproduction, Contraception, Obstetrics and Gynaecology 2015;4(1):215-8.

29. Mercer BM, Gilbert S, Landon MB, et al. Labor outcomes with increasing number of prior vaginal births after caesarean delivery. Obstet Gynecol 2008;111(2 Pt 1):28591.

30. Mozurkewich EL, Hutton EK. Elective repeat caesarean delivery versus trial of labor: a meta-analysis of the literature from 1989 to 1999. Am J Obstet Gynecol 2000;183(5):1187-97.

31. RCOG Green top guideline No. 45. Birth after previous caesarean birth. In RCOG eds. London (UK): RCOG Feb 2007:17.

32. American college of obstetricians and gynecologists committee on obstetric practice bulletins. ACOG Practice Bulletin No. 54: Vaginal birth after previous caesarean delivery. Obstet Gynecol 2004;104(1):203-12. 